Raman, S and French, T (Accepted Manuscript, 14 January 2021)

\title{
Enabling Genuine Participation in Co-design with Young People with Learning Disabilities
}

Sneha Raman and Tara French

The Innovation School, The Glasgow School of Art, Glasgow, U.K.

167 Renfrew St, Glasgow G3 6RQ

s.raman@gsa.ac.uk 
Raman, S and French, T (Accepted Manuscript, 14 January 2021)

\title{
Enabling Genuine Participation in Co-design with Young People with Learning Disabilities
}

\author{
This paper shares key learnings and emerging principles on ways of enabling \\ genuine participation from young people with learning disabilities in co-design. \\ Reviewing previous research focusing on co-design with young people and \\ people with learning disabilities, we highlight key gaps including - a lack of \\ approaches engaging young people with learning disabilities throughout a co- \\ design process; and limited examples of genuine participation focusing on lived \\ experience and engagement in creative and conceptual decision-making. We \\ present our work with young people with learning disabilities to design a game- \\ based learning tool, with a focus on the co-design process. The work illustrates a \\ situated, tailored Participatory Design approach for engaging participants across \\ all stages of co-design. Findings highlight the importance of contextual \\ preparation by embedding in situ to support multi-vocal, multi-method \\ engagement; and asset-based narratives to empower young people and support \\ expression of voice, enabling creativity and conceptual decision-making. \\ Synthesising key learnings and reflections, we present emerging principles \\ underpinned by a rights-based ethos, with an emphasis on creating the right \\ conditions and developing capacities to enable genuine participation.
}

Keywords: co-design; young people with learning disabilities; creativity; conceptual decision-making; genuine participation; rights-based ethos.

\section{Introduction}

The work presented in this paper used a Participatory Design (PD) approach (Sanders et al. 2010; Bratteteig et al. 2012) to co-design a game-based learning (GBL) tool about online safety with young people with learning disabilities (Raman and French 2015). Integrating multiple perspectives, particularly lived experience, is important when designing with people with different abilities (Brereton et al. 2015). In recent years, while the number of studies engaging people with a broad range of abilities in co-design has been growing, very few have specifically focused on learning disabilities (ibid). There is also a high proportion of studies sharing insights on PD with children, but 
Raman, S and French, T (Accepted Manuscript, 14 January 2021)

substantially fewer studies focusing on young people and their involvement in developing new ideas (Sustar et el. 2013). This paper addresses the need to develop PD approaches and guiding principles for engaging specific target groups (Druin 2002; Hendriks et al. 2015; Constantin et al. 2019). A key consideration is the level of participation and nature of engagement in co-design. A wide range of studies labeled as following a PD approach provide 'multiple (and sometimes conflicting) definitions'e.g., PD as 'involvement of end users as informants' and 'going beyond simply engaging people as informants' (c.f. Benton and Johnson 2015). The role of children and young people with learning disabilities in many of these processes remains passive (Börjesson et al. 2015) or limited to one-off sessions (Benton and Johnson 2015). This limits the creative contribution and conceptual decisions integral to a co-design process (Frauenberger et al. 2011). 'Genuine participation', which underpins the democratic principles in PD (Cozza, Cusinato and Philippopoulos-Mihalopoulos 2019), should ensure 'the fundamental transcendence of the users' role from being merely informants to being legitimate and acknowledged participants in the design process' (Robertson and Simonsen, as cited in ibid). To enable legitimate participation, creating a meaningful frame that reflects the participants' everyday lives is also crucial (Iversen and Brodersen 2008). This paper focuses on genuine participation of young people with learning disabilities in PD framed around their lived experience, and enabling participation throughout the co-design process emphasising engagement in creative and conceptual decision-making.

\subsection{Challenges and approaches to co-design with young people with learning}

\section{disabilities}

Traditional co-design techniques draw upon multiple cognitive and sensory abilities, posing challenges for engagement with people with learning disabilities in the design 
Raman, S and French, T (Accepted Manuscript, 14 January 2021)

process (Slegers et al. 2015). Issues related to practical difficulties (Mazzone et al. 2011; Ibrahim 2018), communication, 'proxy' participants (e.g., parents, teachers), and unequal power relationships are common (Frauenberger et al. 2011).

To overcome barriers and engage young people with learning disabilities as design partners (Gerling et al. 2016), attention to environments and social interactions (Brereton et al. 2015), and modifying co-design methods to meet individual abilities (Hendriks et al. 2015) are deemed important. Developing visual languages (Aldridge 2015) and introducing tasks incrementally (Khaled and Vasalou 2014) have been suggested to support participation. Use of sketches, props, role-playing and low fidelity prototypes have also been recommended to support ideation (Khaled and Vasalou 2014; Gaudion et al. 2015). However, there is often a disconnect in the translation of young people's ideas into design concepts, leading to frustration and disappointment, highlighting the need for shared understanding, partnership, trust (Iversen and Smith 2012), and democratic dialogue (O’Brien and Moules 2007). Assigning specific roles to young people as user, informant, designer and tester in the process (Bossavit and Parsons 2016) has also been recommended. Ibrahim (2018) argues for methodological reflexivity and consideration of children's agendas, enabling multi-vocal and credible knowledge. Therefore, a situated approach and flexibility are needed when focusing on individual rights and needs, rather than a predetermined process (Aldridge 2015), with careful configuration of methods and activities based on engagement (Gaudion et al. 2015).

Supporting mutual learning has also been noted as an important prerequisite for co-design (Slegers et al. 2015). Emphasising mutual learning and legitimising lived experiences to complement 'expert' knowledge (Raman et al. 2017), highlighting resilience over 'vulnerability' (Butler 2015), and promoting voice and empowerment 
Raman, S and French, T (Accepted Manuscript, 14 January 2021)

(Bradbury-Jones et al. 2018), including psychological empowerment (Hussain 2010) contribute towards equalising power relations. This aligns with the view of co-design as an empowerment process enabling the development of different capacities fostering ‘power over', 'power to’, 'power with' and 'power within' (Zamenopoulos et al. 2019).

In addition, ethical considerations such as beneficence (ensuring benefits outweigh demands) is important (Frauenberger et al. 2011). There is a call to explicitly address potential benefits including self-esteem, confidence, social skills and enjoyment (Robb et al. 2017; Schepers et al. 2018) and consider empowerment when evaluating the impact of co-design (ibid; Drain et al. 2018). This aligns with the proposed three dimensions - 'capability, suitability and empowerment'- for evaluating PD with children with special needs, including perceived and evidence-based benefits experienced by participants (Constantin et al. 2019). This also supports the argument for considering outcomes (beyond simply the technology output) that bring about positive changes for the participants (Benton and Johnson 2015) by foregrounding the co-design process as 'people engagement' (Selloni and Rossi 2019).

\subsection{Methodological frameworks and principles}

Most of the existing frameworks for engaging people with cognitive and sensory impairments focus on extreme needs and reduced participation (e.g., engaging children with autism). Limited frameworks exist that focus specifically on young people with learning disabilities in co-design. Qualitative guidance on engaging people with learning disabilities offers practical advice on methods, emphasising the value of including their voices in research (Nind 2008). This largely corresponds to 'power over' and 'power to' (Zamenopoulos et al. 2019), but lacks consideration of power in the context of collaboration and empowerment - 'power with' and 'power within'. More recent frameworks related to co-designing with children and people with cognitive and 
Raman, S and French, T (Accepted Manuscript, 14 January 2021)

sensory impairments take these into account; however, creative contribution and decision-making are not considered. For example, Mazzone (2011) offers a practical 'Who-what-when-where-how' framework for planning and organising co-design with children. In contrast, the "Handlungsspielraum" (HSR translated as "Scope-of-Action" or "Action-Play-Space") offers a theoretical lens along with practical tools for co-design activities with children with different abilities, in their context, children with autism (Makhaeva 2016). HSR frames the creative process through structures and freedoms, creating tailored pathways to enable meaningful contributions from individuals, as well as focusing on the relationships and interactions. Highlighting that it is not feasible to create a single framework for engaging specific groups with sensory and cognitive impairments, Hendriks et al. (2015) promote the idea of method stories, while HSR emphasises the need for open, adaptable frameworks (Makhaeva 2016). We argue the need for both, to provide insight into the co-design process and activities, and to inform conceptual knowledge sharing on PD with specific target groups.

This paper presents insights on our situated and tailored approach to co-design with young people with learning disabilities. We share methods and tools to illustrate how we engaged young people with learning disabilities throughout the co-design process - from mapping lived experiences and needs, exploring ideas, prototyping concepts, testing and refining a proof of concept, and evaluating young people's experience of participation. We discuss our findings and reflections on the conditions that enabled genuine participation from young people, including their engagement in the creative process and decision-making, and the impact experienced by participants. We build on these to share key learnings and emerging principles on ways of enabling genuine participation, to inform development of an open conceptual framework in future work. 
Raman, S and French, T (Accepted Manuscript, 14 January 2021)

\section{Methodology}

Methods and tools were framed using an asset-based approach (Teal and French 2016), to enable participation by focusing on participants' capacities and using tailored methods to nurture creativity and engagement in decision-making. In line with a generative co-design process, all activities were designed to be emergent and configured responding to how participants engaged in the process. With a focus on empowering participants to share their expertise from lived experience, tools were designed using narrative approaches and visual storytelling methods. Tailored, multi-vocal, multimethods were designed to enable young people to tell their own stories and support critical reflection. Table 1 summarises the key stages, defining the intention, corresponding methods and tools, and how this enabled creativity and decision-making.

Table 1. Key stages of the co-design process

\begin{tabular}{|l|l|l|l|}
\hline Stage & Objective & Methods and tools & Creativity and decision- \\
making
\end{tabular}

The Version of Record of this manuscript has been published and is available in CODESIGN Published online: 26 January 2021. 


\begin{tabular}{|c|c|c|c|}
\hline & $\begin{array}{l}\text { behaviours, } \\
\text { concerns, } \\
\text { technology } \\
\text { familiarity, } \\
\text { individual } \\
\text { meaning and } \\
\text { motivations. }\end{array}$ & & \\
\hline $\begin{array}{l}\text { Co-design } \\
\text { session } 2(3 \\
\text { hours) }\end{array}$ & $\begin{array}{l}\text { Mapping } \\
\text { participants' } \\
\text { social network } \\
\text { and identifying } \\
\text { who supports } \\
\text { them to stay safe } \\
\text { online. }\end{array}$ & $\begin{array}{l}\text { Visually mapping } \\
\text { participants' 'trust } \\
\text { circle'. }\end{array}$ & $\begin{array}{l}\text { Tangible artefacts and a shared } \\
\text { visual tool to structure activity, } \\
\text { enable conversations and } \\
\text { decision-making related to } \\
\text { prioritising people in the 'trust } \\
\text { circle'. }\end{array}$ \\
\hline $\begin{array}{l}\text { Co-design } \\
\text { session } 3 \text { ( } 5 \\
\text { hours) }\end{array}$ & $\begin{array}{l}\text { Understanding } \\
\text { barriers and risks, } \\
\text { coping } \\
\text { mechanisms, and } \\
\text { preferable } \\
\text { support tools for } \\
\text { online safety. }\end{array}$ & $\begin{array}{l}\text { Building personas, } \\
\text { identifying problems } \\
\text { in scenarios and } \\
\text { creating solutions, } \\
\text { exploring conceptual } \\
\text { design of the game, } \\
\text { including role play. }\end{array}$ & $\begin{array}{l}\text { Visual tools using an asset- } \\
\text { based, story-telling approach } \\
\text { to support creative responses } \\
\text { to problems, enabling } \\
\text { reflection and decision-making } \\
\text { around appropriate forms of } \\
\text { support and ideation of } \\
\text { solutions. }\end{array}$ \\
\hline
\end{tabular}


Raman, S and French, T (Accepted Manuscript, 14 January 2021)

\begin{tabular}{|c|c|c|c|}
\hline $\begin{array}{l}\text { Co-design } \\
\text { session } 4 \text { ( } 5 \\
\text { hours) }\end{array}$ & $\begin{array}{l}\text { Developing ideas } \\
\text { and prototyping } \\
\text { the GBL tool. }\end{array}$ & $\begin{array}{l}\text { Creating storyboards } \\
\text { and low-fidelity } \\
\text { prototypes using Lego, } \\
\text { craft materials, } \\
\text { photographs, drawing, } \\
\text { 3D game scenarios, } \\
\text { role play and video. }\end{array}$ & $\begin{array}{l}\text { Visual maps and tangible tools } \\
\text { supporting ideation through } \\
\text { story-telling; creating, sharing } \\
\text { and prioritising concepts. }\end{array}$ \\
\hline $\begin{array}{l}\text { Co-design } \\
\text { session } 5 \text { ( } 5 \\
\text { hours) }\end{array}$ & $\begin{array}{l}\text { Reviewing and } \\
\text { refining the proof } \\
\text { of concept. }\end{array}$ & $\begin{array}{l}\text { Testing in pairs, focus } \\
\text { groups. }\end{array}$ & $\begin{array}{l}\text { Visual workbook and peer-to- } \\
\text { peer conversations supporting } \\
\text { critical reflection and feedback } \\
\text { to inform the final output. }\end{array}$ \\
\hline $\begin{array}{l}\text { Evaluating the } \\
\text { co-design } \\
\text { sessions ( } 4 \\
\text { hours) }\end{array}$ & $\begin{array}{l}\text { Capturing } \\
\text { participants' } \\
\text { experience of the } \\
\text { co-design process } \\
\text { and feedback on } \\
\text { design activities } \\
\text { and tools. }\end{array}$ & $\begin{array}{l}\text { Reviewing posters, } \\
\text { tools and artefacts, } \\
\text { rating with stickers, } \\
\text { role play, interviews, } \\
\text { focus group. }\end{array}$ & $\begin{array}{l}\text { Using multi-vocal, multi- } \\
\text { method and visual artefacts to } \\
\text { support reflection and } \\
\text { individual and collective } \\
\text { feedback. }\end{array}$ \\
\hline
\end{tabular}

The study was approved by The Glasgow School of Art Research Ethics

Committee. Eighteen young people with mild to moderate learning disabilities (herein, 'young people' or participants) over 16 years old, and six Local Area Coordinators (LACs) providing training and support volunteered to participate. All young people 
Raman, S and French, T (Accepted Manuscript, 14 January 2021)

participated in all the co-design sessions, and 2-3 LACs attended each session on a rotational basis based on availability. Co-design sessions were scheduled fortnightly and were organised at a local site known to the young people for accessing learning and career support. The same venue was retained across sessions for continuity. Activities were introduced incrementally, with consistent breaks pacing each session comfortably. The space was flexible and tailored based on the scale of engagement and dynamics of different activities within each session - e.g., small tables for design activities, bigger tables for focus groups, space marked out with tape for role play.

\subsection{Contextual preparation}

Researchers discussed the co-design plan and engagement strategies with LACs. Information sheets and consent forms were reviewed with them and refined using visuals and simplified text. All venues for the project were chosen based on LAC's recommendation. To introduce the project to potential participants, researchers met the young people during their routine social sessions organised by LACs - a public library and 'Chips \& Chat' at a food joint. It was observed that some of the young people who regularly attended each of these knew one another and some had existing friendships. The design of the sessions acknowledged these existing dynamics whilst also creating opportunities for young people to interact in wider groups to support collaborative working.

Participants were given a visual diary (Fig.1) prior to attending the first codesign session to log their online activities and gaming preferences using a combination of visuals, simple text and stickers (stars and smileys). 
Raman, S and French, T (Accepted Manuscript, 14 January 2021)

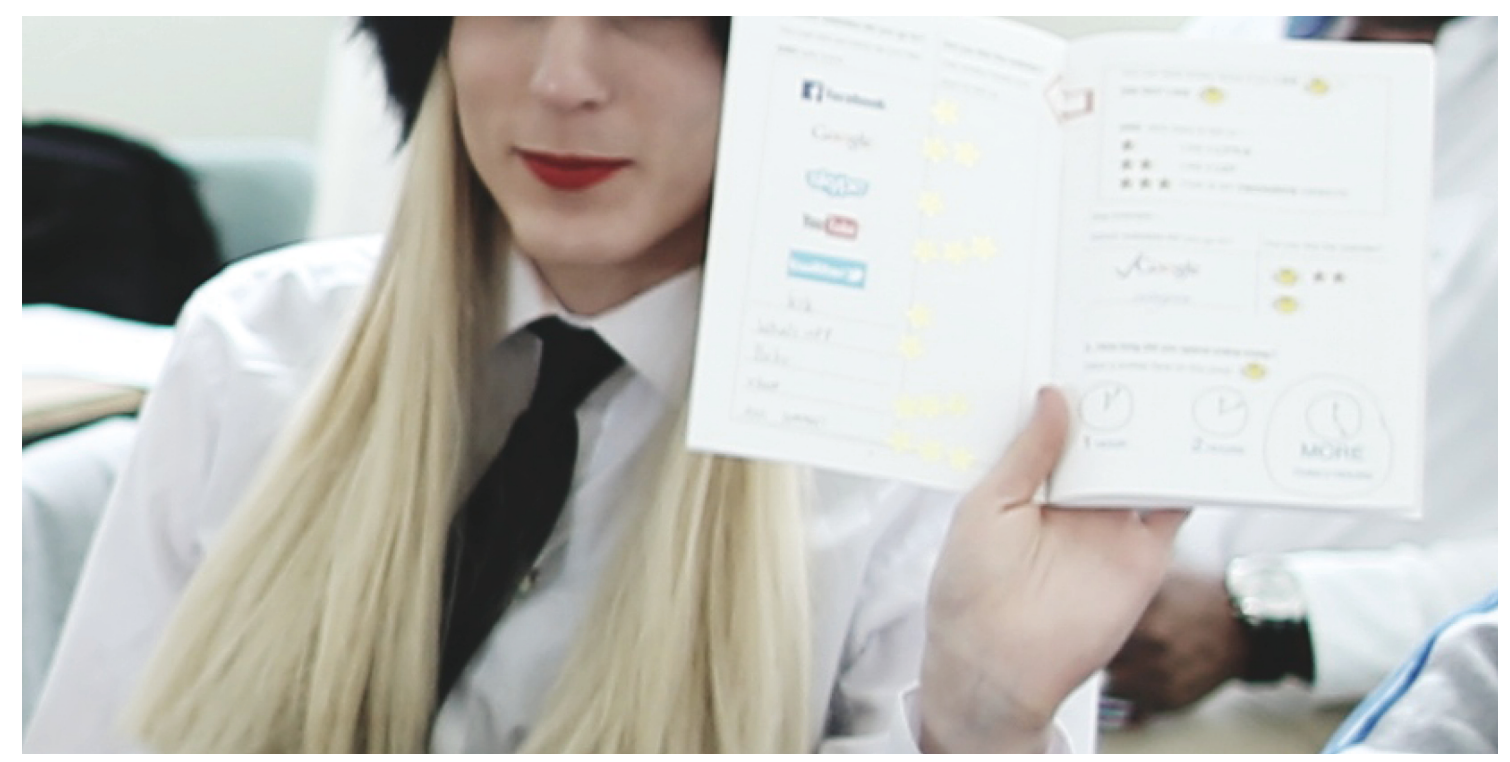

Figure 1. Visual diary. Image Credit: Louise Mather

\subsection{Co-design session 1}

Participants worked in two groups supported by researchers and LACs to share their experience and learning on online safety. Topic 'coasters' (Fig.2) in visual and text format (selected from existing learning material) and blank 'coasters' for new topics, were designed to focus discussion. Participants constructed scenarios with Lego blocks to communicate individual experiences of online safety and learning needs, adding red flags to indicate risks (Fig.2). Researchers and LACs used scenario cards to capture additional details from conversations (e.g., scenario setting, people involved and key issues). 

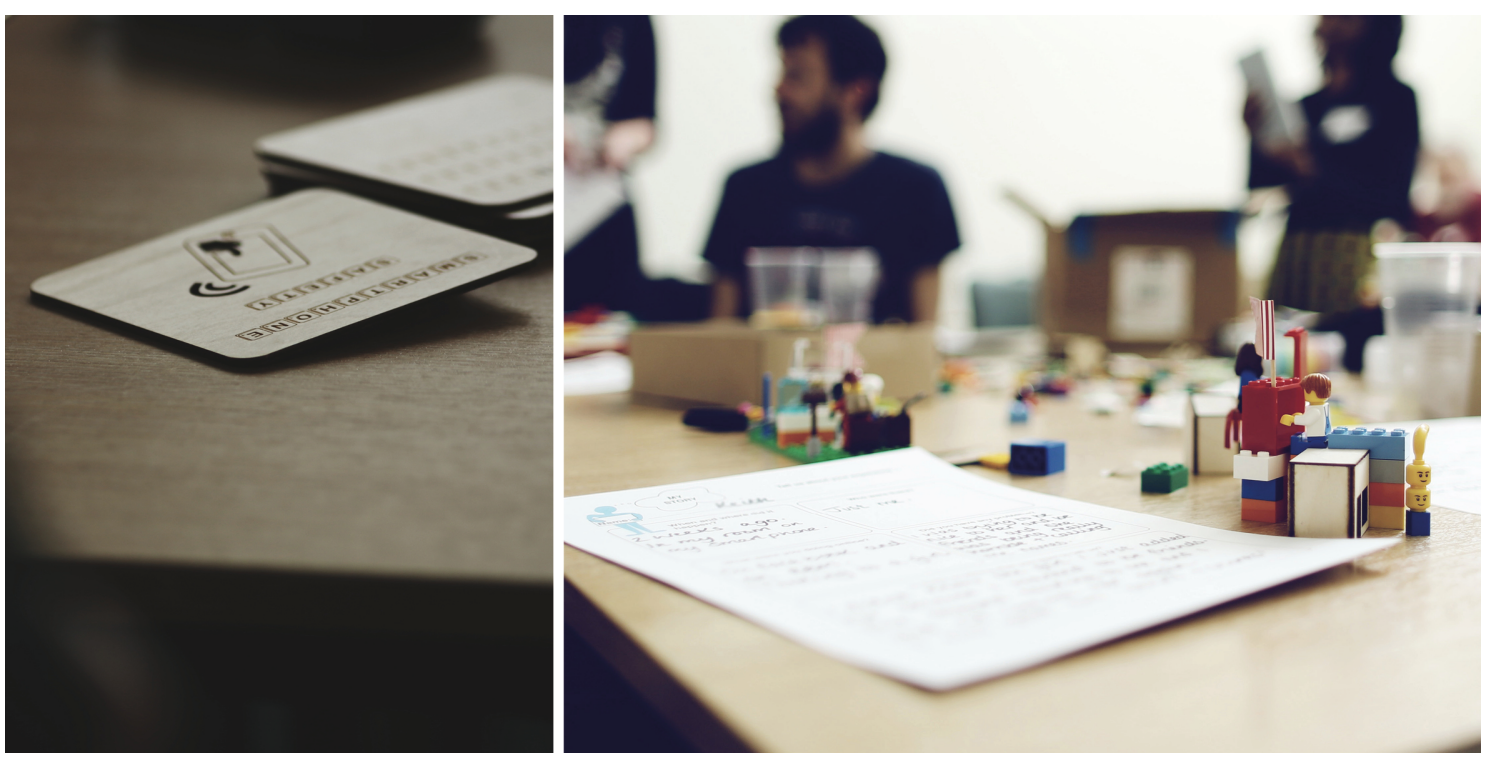

Figure 2. Topic 'coasters', individual experience and scenario card. Image Credit: Louise Mather

\subsection{Co-design session 2}

Participants worked in four groups to build their 'trust circle' using a base map and wooden characters (Fig.3). Each wooden character had space to capture the name/role of the person, and these were placed on the base map closer or away from participant's own character indicating their level of trust. Participants also described why they trusted the person giving examples of support received on online safety, which was captured by researchers and LACs on 'trust' and 'safety' cards (Fig.3). Groups shared their networks by joining together the four base maps similar to a jigsaw. Concentric circles showed varying levels of proximity/trust and helped to identify patterns of social support. 

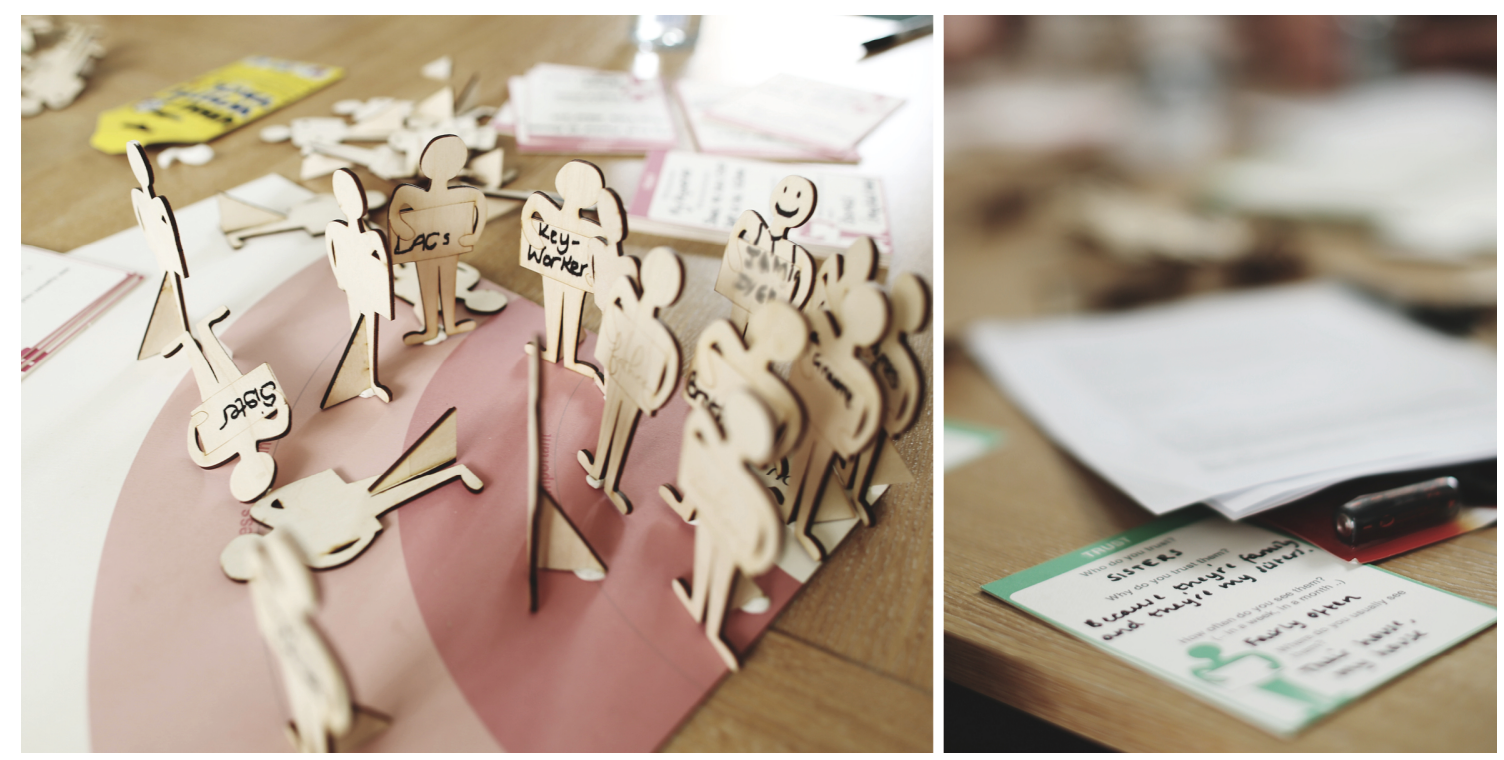

Figure 3. Trust circle and 'trust' and 'safety' cards. Image Credit: Louise Mather

\subsection{Co-design session 3}

Participants created individual 'Superhero badges' (Fig.4) using a template, coloured pens and stickers, and described specific support needs through naming their 'superhero' and describing the 'super tool' that would help them to stay safe. This activity focused on key issues related to identity, confidence, safety and risk when online. Four comic strips were designed based on the experiences shared in previous sessions (Fig.4). Participants worked in four groups, discussing possible ways in which each comic character would act in the situation described. Researchers and LACs captured responses in blank spaces on the comic strips. Participants then selected a 'wild card' revealing challenges on how the character acts in the situation. Participants considered solutions for these based on how their 'superhero' could assist the character. Each group presented their 'superheroes' and solutions (Fig.4), using a choice of materials including props and costumes for roleplay, Lego and puppets. Researchers and LACs helped participants to complete a 'gaming and learning' card, capturing how games help them to learn. Participants worked in small groups to develop initial ideas 
Raman, S and French, T (Accepted Manuscript, 14 January 2021)

for the GBL tool using the cards and reflecting on the challenges and solutions discussed previously. Participants were asked to consider story, setting and characters for the game. Coaster-sized mats (similar to session 1) helped focus discussion.
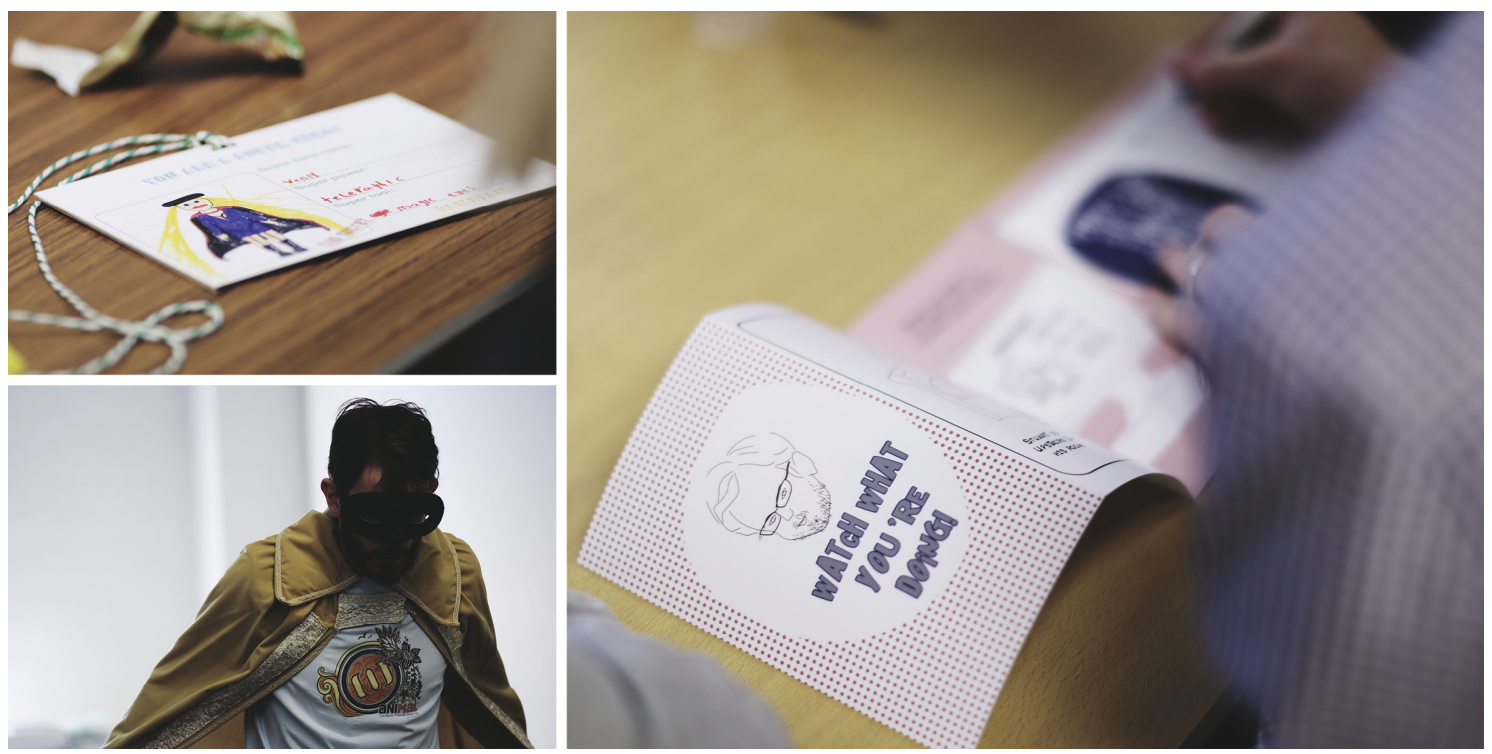

Figure 4. 'Superhero badge', comic strip and role play. Image Credit: Louise Mather

\subsection{Co-design session 4}

A 'stories and solutions' board was created using outcomes from session 3, with colourcoded postcards describing risks (red) and solutions (green). Working in groups, participants selected a story and solution to design the GBL tool and consider who the game could benefit. A storyboard template was designed to build on ideas from session 3 , retaining story, setting and characters to focus discussion. A guide with questions and tips was designed to help the researchers and LACs, and ensure consistency in approach across all groups when designing the game. Groups were given multiple options to present ideas, including Lego, props and craft materials, photos or videos (Fig.5). 

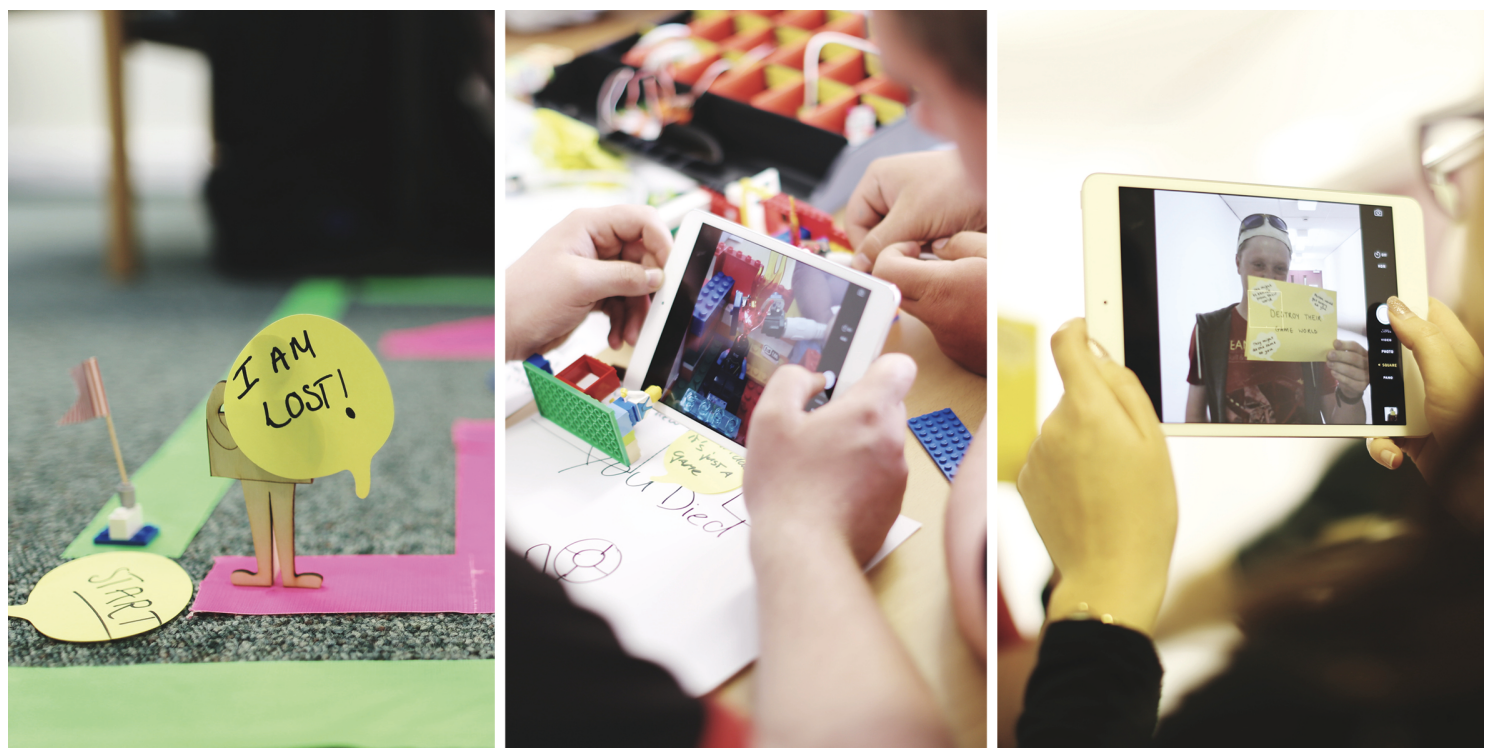

Figure 5. Game concepts and prototypes. Image Credit: Louise Mather

\subsection{Co-design session 5}

Activities were designed to provide participants with a sense of the learning experience to understand whether the GBL tool met their needs (Fig.6). The proof of concept presented a small working prototype of the GBL tool with one scenario based on session 4 concepts. Participants explored the game in pairs, and provided individual feedback using an activity booklet. Ideas from remaining concepts from session 4 were presented to participants as interactive wireframe scenarios on a tablet and printed storyboards. Focus groups with participants and LACs captured feedback on the gaming and learning experience. 

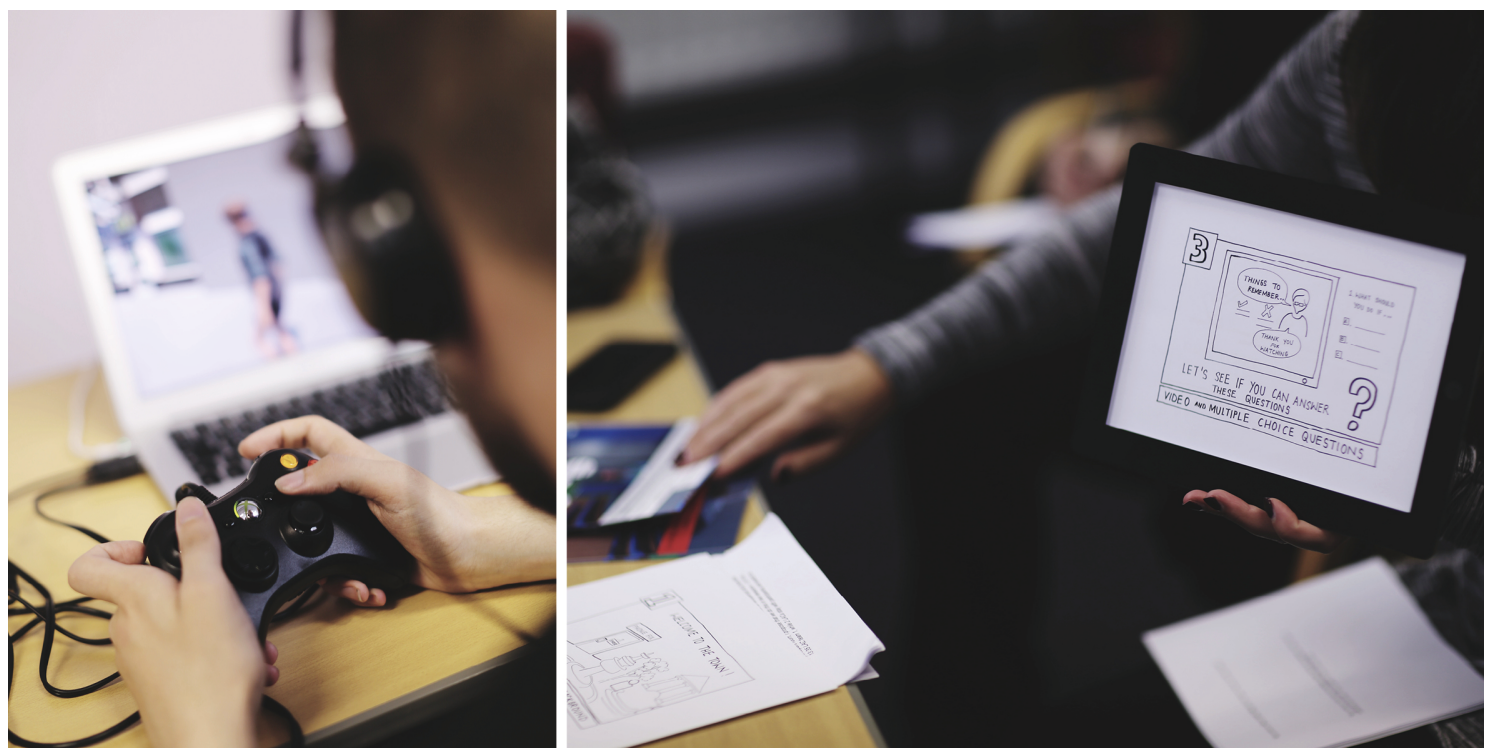

Figure 6. Proof of concept and storyboard. Image Credit: Louise Mather

\subsection{Analysis and design synthesis}

The co-design sessions were designed to support ongoing reflection, synthesis and validation of emerging insights and iteration. Abductive sensemaking approaches (Kolko 2010) supported prioritisation and synthesis of insights and ideas collaboratively with participants during the sessions - especially sessions 3-5 (Table 1), which focused on developing design opportunities from the insights. Using tools such as the comic strips which synthesised participants' lived experiences, 'learning and gaming cards' and 'stories and solutions' board supported sensemaking by externalising and making visible 'what mattered to the young people'. The visual and tangible formats supported young people along with the design researchers to make connections across insights and ideas emerging from the various sessions and guide decision-making by making the process transparent. Analysis on the wall (Sanders and Stappers 2012) was used to organise key insights and themes from the audio transcripts and co-design artefacts in between each co-design session, and further support emerging insights and development of the GBL tool. 
Raman, S and French, T (Accepted Manuscript, 14 January 2021)

\subsection{Evaluating the co-design sessions}

Activity stations with tools, artefacts and outcomes from each session were created to support reflection and feedback on young people's experience of participation in codesign (Fig.7). Young people worked in two groups with a design researcher and LAC, to reflect on and review the activities from each session. At each station, participants used stickers (stars and smileys) to rate activities based on comprehension and ease, contribution to learning, and overall experience. Participants also responded to statements reflecting the ethos of the approach (e.g., 'I felt safe', 'I felt listened to') and emerging benefits highlighted in participants' previous feedback (e.g., 'I made new friends'). Design researchers scribed the qualitative discussions on the posters to reflect additional feedback. Young people shared their experiences following participation in the project through individual scenarios using multi-methods similar to previous sessions, and engaged in dialogue with the researchers about their scenarios. They expanded on their feedback during a short individual interview. LACs also added their reflections on the posters and shared feedback in a focus group.
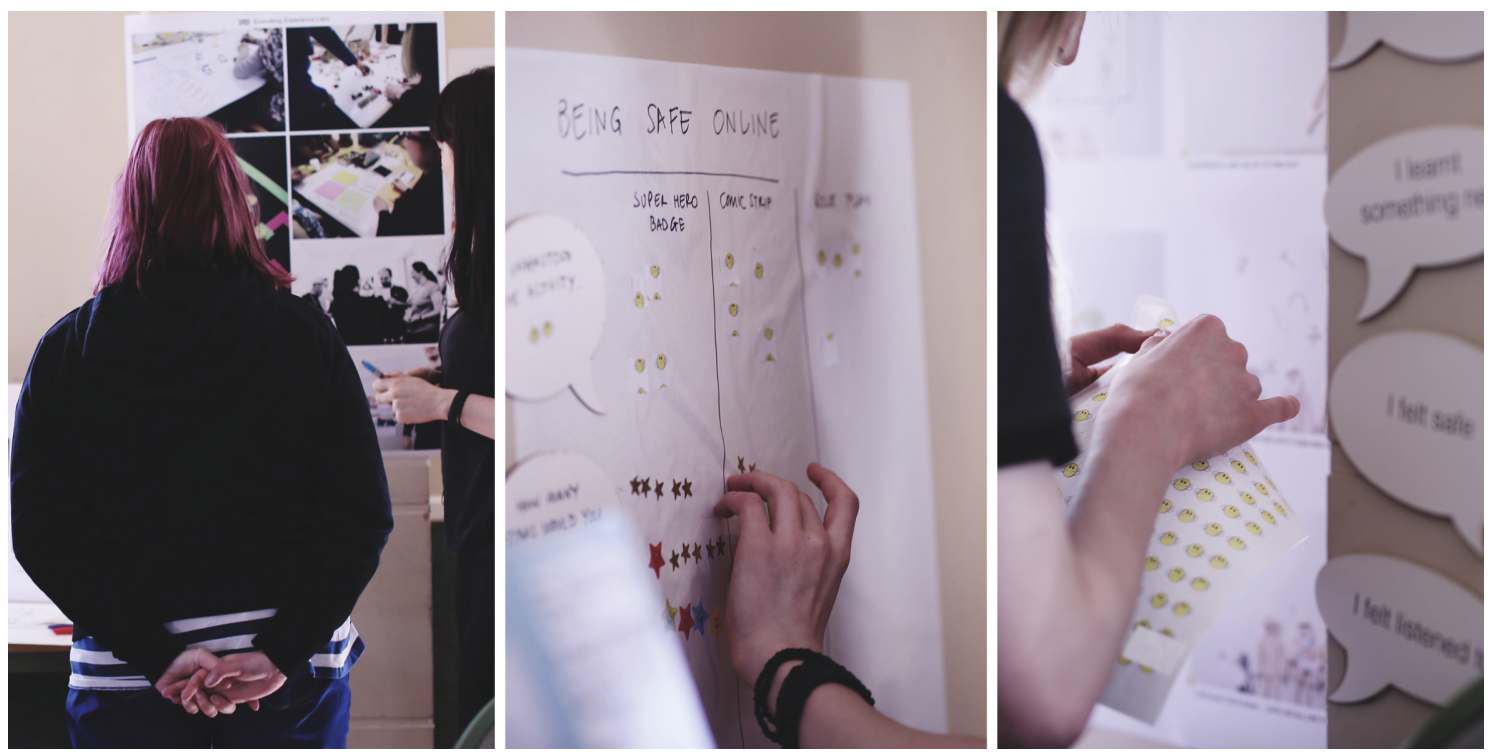

Figure 7. Rating co-design activities and experience. Image Credit: Louise Mather 
Raman, S and French, T (Accepted Manuscript, 14 January 2021)

\subsection{Analysing the feedback}

Audio transcripts and participant feedback were analysed thematically, capturing emergent and recurring themes related to young people's experience of participation i.e., reflections on the co-design methods and tools used in enabling participation, and personal and social experiences of taking part. The scenarios visualised by participants during the evaluation session offered an experiential understanding of what the young people felt had been a notable impact of participation in their personal and social lives. We acknowledge the difficulties of linking benefits experienced by young people as a direct result of participation, and that while qualitative approaches are most appropriate it can also be 'messy' (Benton and Johnson 2015). The findings presented below synthesise insights and learnings on young people's engagement in the co-design process and impact experienced by participants that emerged from an analysis of multiple sources including - the audio transcripts and visual artefacts from the codesign sessions, evaluation and interviews with young people; audio transcripts and feedback from the LACs; and our observations and reflections building on our collective experience and informal interactions with young people and LACs.

\section{Findings}

Findings focus on the design and impact of the co-design process, and contribute insights to the following key areas: genuine participation of young people with learning disabilities, engagement in creativity and conceptual decision-making, and impact experienced by participants.

\subsection{Genuine participation of young people with learning disabilities in co- design}

Contextual preparation emerged as key to gaining an understanding of ways to create

The Version of Record of this manuscript has been published and is available in CODESIGN Published online: 26 January 2021. http://www.tandfonline.com/10.1080/15710882.2021.1877728 
Raman, S and French, T (Accepted Manuscript, 14 January 2021)

the right conditions for engagement, from our reflections on the process. Preparation with the LACs enabled researchers' skills for engaging participants with respect and sensitivity, and guided the design of methods and tools. Meeting the young people in a relaxed social setting, paying attention to their needs and respecting their choice to participate helped researchers in establishing trust and fostering a collaborative relationship. One participant also described this as a 'stepping stone' for participation, during the interviews.

While the familiar setting for the sessions made it accessible to participants, we observed that the neutral space devoid of existing learner-trainer power dynamics supported collaboration. During the focus group, one LAC noted that equality and balance of power resulted from everyone bringing their own knowledge and expertise. LACs also observed that the depth of engagement in the co-design process was not something that young people were used to, and it made the young people feel valued and respected by being acknowledged as 'experts' on themselves.

\footnotetext{
'Equal is the right word because I think the (young people) had the knowledge of what they needed to learn and what they needed to see happen and we had the knowledge of trying to facilitate them being there (...) there's a respect within the room and that's not something that they are used to; they are used to having people being more 'expert' than they are and in an almost kind of patronising way that 'how much would you have to offer?' Whereas it definitely wasn't like that.' - LAC
}

We observed a good level of engagement throughout all stages, through repeated attendance and ongoing participant feedback, further evidenced during evaluation. The focus group with LACs revealed that all participants were motivated to voluntarily attend each session and the fortnightly engagement became part of their routine. On reflection, focusing on continuity and consistency when designing the schedule and format of engagements also helped to sustain participation throughout the project. The 
Raman, S and French, T (Accepted Manuscript, 14 January 2021)

LACs further reported that participation in co-design generated surprising levels of enthusiasm and excitement among the young people, which extended to other meetings with community workers.

Embedding learning opportunities gave young people confidence and provided reassurance on their ability to participate. This is further supported by feedback from participants on learning in the section 'Impact experienced by participants' below. One participant noted during the interview that the sessions gave them opportunity to try something new, which they previously thought was not possible. We observed that the social element of participation, facilitated through building in time for participants to get to know each other, also encouraged a deeper level of sharing and collaboration.

'I did feel a bit nervous at first but then I felt a lot more comfortable and confident (...) and just kept going on, which was a lot better for myself. So I wasn't really sitting there shaking... I had a lot of other people around to talk to, to share all the ideas with.' - Participant

Visual diaries helped to test the format and language at the start, providing insight into individual abilities and preferences. We observed that aesthetic consistency in the design of tools and artefacts, and repetition of materials including stars and smileys, Lego and role-play props, supported visual and cognitive continuity. During the focus group LACs noted that using simple language, minimal text, visuals and objects enabled communication, comprehension, enjoyment and meaning for participants, capturing a true representation of voices. Our observations further highlighted that the multi-vocal, multi-method approach offered each participant choice in sessions to engage and share in a way that was most comfortable, whilst also enabling dialogue and collaboration. 
Raman, S and French, T (Accepted Manuscript, 14 January 2021)

\subsection{Engagement in creativity and conceptual decision-making}

Empowering participants to be creative and participate meaningfully in conceptual decision-making was supported throughout. Activities and tools were designed to ensure that young people were able to express their thoughts and ideas themselves. Using complimentary tools to support individual expression and collaboration helped to strengthen the meaning and purpose of the activities and made engagement less daunting. For example, in session 1 it was observed that the Lego activity supported individual expression of lived experiences, while the scenario cards facilitated dialogue. Many of these tools used asset-based story-telling and narrative formats, enabling young people to explore creative responses to real-life scenarios. For example, the 'superhero' activity helped participants think beyond everyday challenges towards imagining new possibilities. This was visible in participants' responses captured in the comic strips and taken forward by them in the concepts. Designed based on participants' preferences captured in the visual diaries, and using an asset-based narrative focusing on capacities, the 'superhero' and comic strip activities offered an engaging and fun way to explore alternative scenarios creatively. Narrating participant stories through comic strip characters also made discussing personal experiences less intimidating. One participant noted during the interview that using materials such as Lego to share stories ensured they could be themselves and not feel judged.

Visual tools and artefacts synthesised emerging insights and ideas from each session, ensuring conceptual decision-making was transparent and provided everyone an opportunity to contribute. It was observed that materials including the 'stories and solutions' board, storyboards and guide provided structure for developing GBL ideas relevant to the learning needs, whilst using Lego and role-play enhanced freedom in the creative process. Tools such as Lego, photos and videos enabled participants to imagine 
Raman, S and French, T (Accepted Manuscript, 14 January 2021)

and communicate the gaming experience. From the multiple options offered to present their concepts in session 4, all participants chose to role-play. They also chose this method among others while sharing their experiences during evaluation. On reflection, this suggests that young people were able to make an informed choice between different types of methods and tools that supported their creative expression. Participants used low-fidelity prototyping to develop four GBL tool concepts and were able to see their ideas materialised in the proof of concept. This was found to be rewarding by participants, and during the interviews and focus group they expressed satisfaction and a sense of achievement as the game would also help others.

"We didn't know what .. like .. it would come out with - the game, if everybody likes it or...but finally everybody liked the game, which was good." - Participant

Tools and activities also supported participants to reflect on ways of learning. The concepts created by participants suggested that reflecting on how they learn through games they play helped in considering how the GBL tool could support learning about online safety. Insights on how games currently supported young people in their everyday life captured in the 'gaming and learning' cards were reflected in these concepts and further integrated in the proof of concept.

\subsection{Impact experienced by participants}

Throughout the process, young people informally shared positive experiences of participation in co-design on their personal and social lives. This was specifically explored during evaluation to understand impact experienced by participants, where they highlighted key benefits related to learning, ownership, and making friends.

Some participants shared they were able to be more creative and learn by engaging in the activities. This feedback and our observation of young people's 
Raman, S and French, T (Accepted Manuscript, 14 January 2021)

responses during activities e.g., flagging risks during session 1, suggested that the tools supported reflection and understanding of translating learning into everyday scenarios. Many participants shared that since taking part in the sessions they were more conscious of online safety.

“ (...) it's giving me strength and power and power (...) I'm getting better now but I used to have a lot of problems (...) like looking up things I shouldn't look up, I know I still do it but this does help me learn to be safe." - Participant

It was observed that seeing their contributions being valued offered young people greater confidence in their ability to participate in the process and participants expressed a greater ownership over the outcomes. During the interviews participants also described social benefits such as making new friends, sharing that the value of these friendships extended beyond the project.

\section{Discussion}

This paper set out to address the issue of genuine participation of young people with learning disabilities in PD, by framing participation around their lived experience, and enabling participation throughout the co-design process emphasising engagement in creative and conceptual decision-making.

Findings support the emphasis on process and benefit for participants over output to create the right conditions (Selloni and Rossi 2019; Benton and Johnson 2015) to enable genuine participation. Contextual preparation played a crucial role in supporting a rights-based ethos in co-design - by promoting and respecting young people's choice to participate, and designing appropriate ways of engaging to enable this. It was crucial in tailoring methods and tools based on individual ability and engagement (Guha et al. 2008; Gaudion et al. 2015), and appropriating the environment 
Raman, S and French, T (Accepted Manuscript, 14 January 2021)

and interactions (Brereton et al. 2015). It also ensured that the design of the process was informed by young people's motivations (Ibrahim 2018) and collective needs (Hendriks et al. 2015). Designing time and opportunities for building trust, partnership (Iversen and Smith 2012), mutual learning (Slegers et al. 2015; Raman et al. 2017), social experiences and prioritising the pace based on what was comfortable to young people instead of project deadlines, were all integral for sustaining engagement.

Findings also support the use of a multi-vocal, multi-method approach (Ibrahim 2018), and tailoring of engagements to support individual forms of expression (Butler 2015; Makhaeva 2016). Based on feedback and reflections, asset-based narrative and storytelling approaches supported participants to express their lived experience and reflect in their own way, and creatively explore new ideas by building on these. This was also key in developing individual capacities to shape decisions (Bradbury-Jones et al. 2018; Zamenopoulos et al. 2019), empowering young people and equalising power relations (Bradbury-Jones et al. 2018; Gerling et al. 2016). Situated and tailored methods, tools and mindsets enabled methodological reflexivity and flexibility (Ibrahim 2018; Aldridge 2015). Young people were able to alternate between roles independently across different sessions (e.g., informant, co-designer, tester) rather than being 'assigned' a role (Bossavit and Parsons 2016). Enabling direct contribution from the young people, making decisions transparent using visual language (Aldridge 2015), and tools enabling reflective action and dialogue (O'Brien and Moules 2007) throughout the process removed any potential disconnect in the translation of ideas into design concepts (Iversen and Smith 2012). This is fundamental in supporting participants to engage in the creative process and contribute to conceptual decision-making.

Findings also show that participants' experience and benefits of engagement in PD align with those of previous research (Benton and Johnson 2015; Drain et al. 2018; 
Raman, S and French, T (Accepted Manuscript, 14 January 2021)

Constantin 2019) around beneficence (Frauenberger et al. 2011), empowerment

(Hussain 2010; Drain et al. 2018), and personal and social benefits (Robb et al. 2017;

Schepers et al. 2018).

Synthesising these key learnings and reflections, we propose emerging

principles on ways of enabling genuine participation in co-design with young people

with learning disability in the future.

Table 2. Key learnings and emerging principles on ways of enabling genuine participation

\begin{tabular}{|l|l|}
\hline Key learnings & Emerging principles \\
\hline Making an ethical commitment to enable individuals to & Fostering a rights-based ethos \\
shape decisions throughout the process by supporting & through a situated, tailored approach \\
reflection and informed choices. & \\
\hline Appropriating methods and tools to enable individual & Designing the right conditions \\
creativity and conversations; designing time, & through embedding in context \\
opportunities for mutual learning and social experiences, & \\
to build trust and foster equal partnerships. & Facilitating creative expression \\
\hline Enabling sharing of personal experiences by making & through asset-based approaches \\
\hline visible the expertise of participants and enabling & \\
\hline abilities (not 'disabilities') and designing multi-vocal, & capacities \\
\hline
\end{tabular}

The Version of Record of this manuscript has been published and is available in CODESIGN Published online: 26 January 2021. 
reflection using narrative, storytelling methods.

These emerging principles intend to prompt further dialogue among the wider co-design community. However, they require further validation to understand how these can inform future co-design beyond this project. We invite critical consideration of the process of enabling genuine participation by applying, reviewing and refining principles towards developing a conceptual framework.

\subsection{Limitations and future work}

The methods and tools created opportunities for both individual expression and collective conversations. However, when working in groups many young people tended to mostly agree with their peers and the LACs. Further exploration of multi-vocal, multi-methods enabling expression of individual voices within collaborative settings is required. The emerging principles on ways of enabling genuine participation are based on findings from a single project working with young people with learning disabilities. Future work will focus on reviewing methodological frameworks and shared principles, building on the experience of undertaking a range of co-design projects working with groups with different abilities and sensitivities.

\section{Conclusion}

This paper shares findings and emerging principles on ways of enabling genuine participation in co-design with young people with learning disabilities, supporting participation throughout all stages and engagement in creativity and decision-making.

We argue for a rights-based ethos providing choice and developing capacities to facilitate genuine participation through a tailored, situated PD approach. We 
Raman, S and French, T (Accepted Manuscript, 14 January 2021)

demonstrate the importance of contextual preparation by embedding in situ to support multi-vocal, multi-method engagement to empower young people and support expression of voice. The emerging principles offer learnings to guide future co-design towards developing a conceptual framework with an emphasis on - creating the right conditions for genuine participation, empowerment and expression of voice to shape decisions, and asset-based narrative approaches to facilitate creative expression.

\section{Notes}

Findings on the design output (GBL tool) are published in another paper (Usoro, Idong, Connolly, Thomas, Raman, Sneha, French, Tara, and Caulfield, Stuart. 2016. "Using games based learning to support young people with learning disabilities stay safe online.” In Proceedings of the 10th European Conference on Games Based Learning, 704-712.).

\section{Acknowledgements}

We thank all the young people who volunteered their valuable time to take part, and for sharing their experiences, ideas, energy and enthusiasm, without which this project would not have been possible. We are also grateful to the Local Area Coordinators and project partners, Stuart Caulfield (Midlothian Council) and Idong Usoro (University of West of Scotland), for their collaboration, contributions and support. We would also like to thank the anonymous reviewers for their careful reading of our manuscript and the valuable comments that helped us in refining this paper for publication.

\section{Disclosure statement}

No potential conflict of interest was reported by the authors.

\section{Funding}

This work was supported by the Digital Health and Care Institute funded by the Scottish Funding Council.

\section{References}

Aldridge, Jo. 2015. Participatory research: Working with vulnerable groups in research and practice. UK: Policy Press. 
Raman, S and French, T (Accepted Manuscript, 14 January 2021)

Benton, Laura, and Johnson, Hilary. 2015. "Widening Participation in Technology Design: A review of the involvement of children with special educational needs and disabilities." International Journal of Child-Computer Interaction 3-4: 23 40.

Börjesson, Peter, Barendregt, Wolmet, Eriksson, Eva, and Torgersson, Olof. 2015. "Designing technology for and with developmentally diverse children: a systematic literature review." In Proceedings of the 14th International Conference on Interaction Design and Children, 79-88. New York: Association for Computing Machinery.

Bossavit, Benoît, and Parsons, Sarah. 2016. ““"This is how I want to learn” High Functioning Autistic Teens Co-Designing a Serious Game.” In Proceedings of the 2016 CHI Conference on Human Factors in Computing Systems, 1294-1299. San Jose USA.

Bradbury-Jones, Caroline, Isham, Louise, and Taylor, Julie. 2018. "The complexities and contradictions in participatory research with vulnerable children and young people: A qualitative systematic review." Social Science \& Medicine 215: 8091.

Bratteteig, Tone, Bødker, Keld, Dittrich, Yvonne, Mogensen, Preben Holst, and Simonsen, Jesper. 2012. "Methods: Organising principles and general guidelines for participatory design projects." In Routledge international handbook of participatory design, edited by Simonsen, J and Robertson, T, 137-164. New York: Routledge.

Brereton, Margot, Sitbon, Laurianne, Abdullah, Muhammad Haziq Lim, Vanderberg, Mark, and Koplick, Stewart. 2015. "Design after design to bridge between people living with cognitive or sensory impairments, their friends and proxies." CoDesign 11 (1): 4-20.

Butler, Vikki. 2015. Scoping paper on participatory research methodologies for creating a research model to work with vulnerable young people. Swansea: CARP Collaborations.

Constantin, Aurora, Korte, Jessica, Fails, Jerry Alan, Good, Judith, Alexandru, Cristina Adriana, Dragomir, Mihaela, Pain, Helen, Hourcade, Juan Pablo, Eriksson, Eva, Waller, Annalu, and Garzotto, Franca. 2019. "Pushing the Boundaries of Participatory Design with Children with Special Needs.” In Proceedings of the 
Raman, S and French, T (Accepted Manuscript, 14 January 2021)

18th ACM International Conference on Interaction Design and Children, 697705. New York: Association for Computing Machinery.

Cozza, Michela, Cusinato, Augusto, and Philippopoulos-Mihalopoulos, Andreas. 2019. “Atmosphere in Participatory Design.” Science as Culture 29 (2): 269-292.

Drain, Andrew, Shekar, Aruna, and Grigg, Nigel. 2018. "Insights, Solutions and Empowerment: a framework for evaluating participatory design.” CoDesign 121. https://doi.org/10.1080/15710882.2018.1540641

Druin, Allison. 2002. "The role of children in the design of new technology." Behaviour and information technology 21 (1): 1-25.

Frauenberger, Christopher, Good, Judith, and Keay-Bright, Wendy. 2011. "Designing technology for children with special needs: bridging perspectives through participatory design." CoDesign 7 (1): 1-28.

Gaudion, Katie, Hall, Ashley, Myerson, Jeremy, and Pellicano, Liz. 2015. “A designer's approach: how can autistic adults with learning disabilities be involved in the design process?.” CoDesign 11 (1): 49-69.

Gerling, Kathrin, Hicks, Kieran, Kalyn, Michael, Evans, Adam, and Linehan, Conor. 2016. "Designing movement-based play with young people using powered wheelchairs." In Proceedings of the 2016 CHI Conference on Human Factors in Computing Systems, 4447-4458. San Jose USA.

Guha, Mona Leigh, Druin, Allison, and Fails, Jerry Alan. 2008. "Designing with and for children with special needs: an inclusionary model." In Proceedings of the 7th international conference on Interaction design and children, 61-64. Chicago.

Hendriks, Niels, Slegers, Karin, and Duysburgh, Pieter. 2015. “Codesign with people living with cognitive or sensory impairments: a case for method stories and uniqueness." CoDesign 11 (1): 70-82.

Hussain, Sofia. 2010. "Empowering marginalised children in developing countries through participatory design processes." CoDesign 6 (2): 99-117.

Ibrahim, Seray. 2018. "Reflexively Applying PD Methods Toward Understanding Child-Centred Accounts of Communication." In Workshop on Giving A Voice Through Design: Adapting Design Methods to Ensure the Participation of People with Communication Difficulties at PDC 2018. Brussels.

Iversen, Ole Sejer, and Brodersen, Christina. 2008. "Building a BRIDGE between children and users: a socio-cultural approach to child-computer interaction." Cognition Technology and Work 10: 83-93.

The Version of Record of this manuscript has been published and is available in CODESIGN Published online: 26 January 2021. http://www.tandfonline.com/10.1080/15710882.2021.1877728 
Raman, S and French, T (Accepted Manuscript, 14 January 2021)

Iversen, Ole Sejer, and Smith, Rachel Charlotte. 2012. "Scandinavian Participatory Design: Dialogic curation with Teenagers." In Proceedings of Interaction Design and Children. New York.

Khaled, Rilla, and Vasalou, Asimina. 2014. "Bridging serious games and participatory design.” International Journal of Child-Computer Interaction 2 (2): 93-100.

Kolko, Jon. 2010. "Abductive thinking and sensemaking: The drivers of design synthesis." Design issues 26 (1): 15-28.

Makhaeva, Julia, Frauenberger, Christopher, and Spiel, Katta. 2016. "Creating creative spaces for co-designing with autistic children”. In Proceedings of the 14th Participatory Design Conference 1: 51-60. Aarhus Denmark.

Mazzone, Emanuela, Read, Janet C., and Beale, Russell. 2011. "Towards a framework of co-design sessions with children." In IFIP Conference on Human-Computer Interaction, 632-635. Berlin: Springer.

Nind, Melanie. 2008. Conducting qualitative research with people with learning, communication and other disabilities: Methodological challenges. National Centre for Research Methods Publications. UK: University of Southampton.

O'Brien, Niamh, and Moules, Tina. 2007. "So round the spiral again: A reflective participatory research project with children and young people." Educational Action Research 15 (3): 385-402.

Raman, Sneha, and French, Tara. 2015. Game Jam. UK: The Glasgow School of Art.

Raman, Sneha, French, Tara, and Tulloch, Angela. 2017. "Design-led Approach to Coproduction of Values for Collective Decision-Making." The Design Journal 20 (1): S4331-S4342.

Robb, Nigel, Leahy, Michael, Sung, Connie, and Goodman, Lizbeth. 2017.

"Multisensory Participatory Design for Children with Special Educational Needs and Disabilities." In Proceedings of the 2017 Conference on Interaction Design and Children, 490-496. New York: Association for Computing Machinery.

Sanders, Elizabeth, B.N., and Stappers, Pieter Jan. 2012. Convivial toolbox: generative research for the front end of design. Amsterdam: BIS Publishers.

Sanders, Elizabeth B.N., Brandt, Eva, and Binder, Thomas. 2010. “A Framework for Organizing the Tools and Techniques of Participatory Design." In Proceedings of the 11th Biennial Participatory Design Conference, 195-198. Sydney.

Schepers, Selina, Dreessen, Katrien, and Zaman, Bieke. 2018. "Exploring user gains in participatory design processes with vulnerable children." In Proceedings of the 
Raman, S and French, T (Accepted Manuscript, 14 January 2021)

15th Participatory Design Conference: Short Papers, Situated Actions, Workshops and Tutorial, (2): 1-5. Hasselt and Genk Belgium.

Selloni, Daniela, and Rossi, Martina. 2019. "Design for social innovation within a vulnerable group. Lessons learnt from the experimentation ViviCalusca in Italy.” In 3rd LeNS World Distributed Conference, 2: 564-569. Milan.

Slegers, Karin, Duysburgh, Pieter, and Hendriks, Niels. 2015. "CoDesign with people living with cognitive and sensory impairments." CoDesign 11 (1): 1-3.

Sustar, Helena, Bowen, Simon, Dearden, Andy, Fisher, Mark, and Wolstenholme, Dan. 2013. "Using popular culture to enable health service co-design with young people.” In Crafting the Future European Academy of Design Conference. Sweden: EAD.

Teal, Gemma, and French, Tara. 2016. "Designed Engagement.” In Design+ Research+ Society-Future-Focused Thinking: 50th Anniversary Conference of the Design Research Society, 3653-3668. Brighton: Design Research Society.

Zamenopoulos, Theodore, Lam, Busayawan, Alexiou, Katerina, Kelemen, Mihaela, De Sousa, Sophia, Moffat, Sue, and Phillips, Martin. 2019. "Types, obstacles and sources of empowerment in co-design: the role of shared material objects and processes." CoDesign, 1-20. https://doi.org/10.1080/15710882.2019.1605383 